\title{
Ketepatan Penentuan Kode Penyebab Dasar Kematian Pasien di Rumah Sakit Umum Daerah Kota Salatiga Triwulan IV Tahun 2010
}

\author{
Yuniana Eka Pratiwi \\ Mahasiswa APIKES Mitra Husada Karanganyar \\ Yuniana_EP@ymail.com
}

\begin{abstract}
ABSTRAK
Penentuan kode Penyebab Dasar kematian merupakan salah satu fungsi yang penting dari fungsifungsi unit kerja rekam medis yang membutuhkan ketelitian. Dalam menentukan kode Penyebab Dasar kematian, petugas harus memperhatikan prosedur atau Rule yang telah ditetapkan oleh WHO di dalam ICD-10 volume 2. Tujuan penelitian ini untuk mengetahui ketepatan penentuan kode penyebab dasar kematian di Rumah Sakit Umum Daerah Kota Salatiga Triwulan IV tahun 2010.

Jenis Penelitian ini adalah penelitian deskriptif dengan pendekatan secara retrospektif. Metode penelitian ini adalah wawancara dan observasi. Populasi dan sampel dalam penelitian ini adalah dokumen rekam medis pasien rawat inap yang meninggal triwulan IV di Rumah Sakit Umum Daerah Kota Salatiga tahun 2010 sebanyak 28 dokumen. Tehnik pengambilan sampel yaitu sampling jenuh, dengan analisis data yang digunakan adalah analisis deskriptif.

Hasil penelitian menunjukkan bahwaketepatan hasil penentuan kode penyebab dasar kematian pasien di Rumah Sakit Umum Daerah Kota Salatiga Triwulan IV Tahun kode penyebab dasar kematian yang tepat sebanyak $21(75 \%)$ dan kode penyebab dasar kematian yang tidak tepat sebanyak 7 kode (25\%). Cara menentukan kode penyebab dasar kematian pasien adalah berdasarkan kode dari diagnosis utama yang ditulis dokter dalam status pasien. Hal ini belum sesuai dengan peraturan yang ada pada ICD-10 yaitu dalam menentukan kode penyebab dasar kematian petugas haruslah melakukan reseleksi dengan penerapan Rule, yang meliputi penerapan Prinsip Umum, Rule 1, Rule 2 atau Rule 3.

Cara untuk menghasilkan ketepatan kode penyebab dasar kematian yaitu dengan penerapan prosedur atau Rule sesuai dengan ICD-10 yaitu tentang penentuan kode penyebab dasar kematian. Selain itu perlu dibuat prosedur tetap tentang cara penentuan kode penyebab dasar kematian dan penyediaan tabel Medical Mortality Data System (MMDS) untuk membantu dalam penetapan kode penyebab dasar kematian.
\end{abstract}

\section{Kata Kunci $\quad$ : Kode Penyebab Dasar Kematian, ICD-10, MMDS}

\section{PENDAHULUAN}

Rekam medis adalah berkas yang
berisikan catatan dan dokumen tentang
dentitas pasien, pemeriksaan, pengobatan,
indakan serta pelayanan lain yang telah
diberikan kepada pasien (DepKesRI, 2008).

Rekam medis dikatakan bermutu apabila rekam medis tersebut akurat, lengkap, dapat dipercaya, valid dan tepat waktu (Abdelhak, 2001). Salah satu bentuk pengelolaan dalam rekam medis adalah pendokumentasian serta pengodean (coding) diagnosis.

Pelaksanaan kodefikasi dilakukan oleh seorang perekam medis dengan menggunakan standar klasifikasi yaituICD10. ICD-10 merupakan klasifikasi statistik, yang terdiridari sejumlah kode alphanumerik yang satu sama lain berbeda menurut kategori, yang menggambarkan konsep seluruh penyakit. Klasifikasi dalam ICD-10 mencakup panduan yang berisi 
Rules atau peraturan yang spesifik untuk menggunakannya. Pelaksanaan pengodean diagnosis tersebut harus lengkap dan akurat sesuai dengan arahan ICD-10 (WHO, 2004).

ICD-10 digunakan sebagaidasar dalam mempersiapkan data statistik kematian. WHO menyusunsertifikat kematian yang merupakansumberutama data mortalitas dan digunakan sebagai dasar pembuatan laporan penyebab kematian (Kasim F. dan Ekardius, 2010).Laporan tentang penyebab kematian sangatlah berguna agar rumah sakit dapat membuat klasifikasi tentang penyebab kematian utama yang dapat digunakan untuk evaluasi kualitas pelayanan, kebutuhan tenaga medis dan alat-alat medis.

Berdasarkan survei pendahuluan yang dilaksanakan di Rumah Sakit Umum Daerah Kota Salatiga diketahui bahwa secara umum untuk penentuan kode Penyebab Dasar kematian di Rumah Sakit Umum Daerah Kota Salatiga belum mengacu pada aturan yang ada di ICD-10. Petugas coding menetapkan kode diagnosis utama yang tertulis pada status pasien sebagai kode penyebab dasar kematian tanpa melihat kembali aturan atau Rule yang ada di ICD10 tentang penentuan kode penyebab dasar kematian. Hal ini menyebabkan masih ditemukan adanya ketidaktepatan dalam penentuan kode Penyebab Dasar kematian, yang akan berpengaruh terhadap laporan mortalitas yang berkenaan dengan penyakit, monitoring survei serta dalam trend klasifikasi 10 besar penyakit penyebab kematian. Berdasarkan latar belakang tersebut, peneliti tertarik untuk melakukan penelitian dengan judul"Ketepatan Penentuan Kode Penyebab Dasar Kematian Pasien di Rumah Sakit Umum Daerah Kota Salatiga Triwulan IV tahun 2010”.

Penyebab Dasar Kematian (Underlying Cause of Death) adalah sebab dasar terjadi serentet sebab-sebab kematian. Sebab dasar terjadinya kematian yaitu : Penyakit terjadinya cedera sebagai pemicu serentetan kejadian yang mengakibatkan kematian, kejadian kecelakaan atau kekerasan yang menghasilkan cedera fatal.(Anggraini $M$, 2004)

Tabel Medical Mortality Data System (MMDS) dipakai untuk membantu penetapan penyebab dasar yang benar. Decision tabel ini adalah kumpulan daftar yang memberikan panduan dan arah dalam penerapan Rule seleksi dan modifikasi yang dipublikasikan dalam ICD-10 volume 2 . (DepKes RI, 2008)

\section{METODE PENELITIAN}

Jenis Penelitian ini adalah penelitian deskriptif yang menggambarkan tentang ketepatan penentuan kode penyebab dasar kematian pasien di Rumah Sakit Umum Daerah Kota Salatiga Triwulan IV tahun 2010, dengan pendekatan secara retrospektifdimana peneliti mengumpulkan data-data yang ada pada masa lalu atau yang pernah terjadi.

Variable penelitian adalah ketepatan penentuan kode penyebab dasar kematian yaitu ketentuan pemberian kode penyebab dasar kematian. 
Populasi dalam penelitian ini yaitu dokumen rekam medis pasien rawat inap yang meninggal pada triwulan IV di Rumah Sakit Umum Daerah Kota Salatiga tahun 2010 sebanyak 28 dokumen. Sampel yang digunakan dalam penelitian ini yaitu seluruh dokumen rekam medis pasien rawat inap yang meninggal triwulan IV di Rumah Sakit Umum Daerah Kota Salatiga tahun 2010 sebanyak 28 dokumen dengan menggunakan teknik sampling jenuh.Instrumen Penelitian terdiri dari : Pedoman Wawancara, Pedoman observasi, Cara Pengumpulan Data, Wawancara, Observasi

Analisis data yang digunakan dalam penelitian ini adalah dengan menggunakan analisis diskriptif yaitu dengan cara mendiskripsikan data yang telah dikumpulkan dan diolah menjadi ketepatan penentuan kode penyebab dasar kematian di Rumah Sakit Umum Daerah Kota Salatiga Triwulan IV tahun 2010.

\section{HASIL}

Tata cara pemberian kode di Rumah Sakit Umum Daerah Kota Salatiga Pemberian kode penyakit di Rumah Sakit Umum Daerah Kota Salatiga dilakukan oleh petugas Codingmenggunakan International Statistical Classification of Diseases and Related Health Problems Tenth Revision (ICD-10). Tata cara pengodeannya adalah sebagai berikut:Petugas Codingmenerima bekas dari Assembling. Memberi kode dari diagnosis pasien menggunakan ICD -10 volume 3 dengan melihat alfabetikal indeks.Bila kode pada volume 3 sudah ditemukan dilihat ICD-10 volume 1 untuk memastikan ketepatan kodenya. Kode ditulis pada lembar ringkasan masuk dan keluar kolom diagnosa.Setelah dikoding petugas menyerahkan dokumen ke bagian indeksing untuk dibuat indeks.

Ketepatan Penentuan Kode Penyebab Dasar Kematian di Rumah Sakit Umum Daerah Kota Salatiga Berdasarkan ICD-10. Upaya mengetahui ketepatan penentuan kode dan diagnosis penyebab kematian dengan ICD-10, peneliti melakukan observasi pada dokumen rekam medis pasien meninggal pada triwulan IV tahun 2010. Observasi yang dilakukan peneliti adalah mencocokkan antara hasil penentuan kode diagnosis yang dianggap sebagai kode sebab kematian dengan aturan atau rule menurut prosedur WHO yang ada di ICD10. Data hasil observasi yang telah dilakukan peneliti terhadap data kematian pasien rawat inap triwulan IV tahun 2010 dapat dilihat padalampiran 10 .

Persentase dari keseluruhan data hasil analisis ketepatan penentuan kode Penyebab Dasar kematian pasien di Rumah Sakit Umum Daerah Kota Salatiga Triwulan IV Tahun 2010 dengan jumlah populasi sebanyak 28 angka kematian adalah sebagai berikut:

Tabel 1.Rekapitulasi Ketepatan Hasil Penentuan KodePenyebab Dasar Kematian Pasien 


\begin{tabular}{lll}
\hline Kriteria & Jumlah & Persentase (\%) \\
\hline Tepat & 22 & 78,57 \\
Tidak & 6 & 21,43 \\
Tepat & & \\
\hline Jumlah & 28 & 100 \\
\hline
\end{tabular}

Dari tabel 1 dapat kita lihat bahwa ketepatan hasil penentuan kode Penyebab Dasar kematian pasien di Rumah Sakit Umum Daerah Kota Salatiga Triwulan IV Tahun 2010 adalah sebanyak 22 kode (78,57 $\%)$ sedangkan persentase ketidaktepatannya adalah sebanyak 6 kode $(21,43 \%)$. Penyebab dasar kematian terbesar di Rumah Sakit Umum Daerah Kota Salatiga adalah penyakit Stroke, pada triwulan IV terdapat 9 (Sembilan) pasien meninggal dengan penyebab dasar kematian Stoke (lampiran 10).

Cara Penentuan Kode Penyebab Dasar Kematian di Rumah Sakit Umum Daerah Kota Salatiga. Berdasarkan hasil wawancara yang dilakukan peneliti, diketahui bahwa di Rumah Sakit Umum Daerah Kota Salatiga belum mempunyai prosedur tetap yang berkaitan dengan prosedur penentuan kode penyebab dasar kematian. Penentuan kode penyebab dasar yang dilakukan selama ini di Rumah Sakit Umum Daerah Kota Salatiga belum menggunakan prosedur yang telah ditetapkan oleh World Health Organitation (WHO) maupun Depkes yaitu dengan menggunakanRule atau peraturan yang ada. Penentuan kode penyebab dasar kematian masih berdasarkan kode dari diagnosis utama yang ditulis dokter dalam status pasien.

\section{PEMBAHASAN}

Dari hasil penelitian dapat diketahui bahwa tata cara pengodean di sesuai dengan teori pada ICD-10. Dalam menentukan kode diagnosis utama pasien, petugas coding memperhatikan tunjuk silang (cross references) juga mengikuti inclusion dan exclusion dibawah kode atau dibawah chapteruntuk mendapatkan kode yang tepat. Agar dapat memberikan kode penyakit secara tepat untuk memudahkan dalam pembuatan laporan yang dibutuhkan oleh manajemen rumah sakit, petugas sudah berpedoman pada prosedur tetap pemberian kode penyakit di Rumah Sakit Umum Daerah Kota Salatiga nomor 28/1/07/CM 13 Januari 2007 revisi 1.

Ketepatan Penentuan Kode Penyebab Dasar Kematian di Rumah Sakit Umum Daerah Kota Salatiga Berdasarkan ICD10.Menurut Abdelhak (2001), kesesuaian data dan informasi yang disajikan dengan informasi yang dibutuhkan sangat berperan dalam proses pengambilan keputusan. Untuk dapat menghasilkan data serta informasi yang baik serta dapat digunakan sebagai dasar dalam pengambilan keputusan manajemen, dibutuhkan peran aktif petugas dalam melakukan proses pengolahan data.

Dari hasil penelitian diketahui bahwa ketepatan hasil penentuan kode Penyebab Dasar kematian pasien di Rumah Sakit Umum Daerah Kota Salatiga Triwulan IV Tahun kode penyebab dasar kematian yang tepat sebanyak $22(78,57 \%)$ dan kode penyebab dasar kematian yang tidak tepat sebanyak 6 kode $(21,43 \%)$. 
Ketidaktepatan penentuan kode penyebab dasar kematian ini disebabkan karena petugas menetapkan kode penyebab dasar kematian berdasarkan kode dari diagnosis utama yang ditulis dokter dalam status pasien. Sedangkan menurut teori, untuk menentukan kode penyebab dasar kematian petugas haruslah melakukan reseleksi dengan penerapan Rule, yang meliputi penerapan Prinsip Umum, Rule 1, 2 atau 3.

Cara Penentuan Kode Penyebab Dasar Kematian di Rumah Sakit Umum Daerah Kota Salatiga. Berdasarkan buku DepKes (2008) dijelaskan bahwa dalam penentuan kode penyebab kematian harus mengikuti prosedur atau Rule yang telah ditetapkan. Jika hanya ada satu penyebab kematian yang dilaporkan, maka penyebab tersebut adalah penyebab kematiannya dan digunakan untuk tabulasi. Jika lebih dari satu penyebab kematian yang dilaporkan, maka langkah yang digunakan pertama kali yaitu menentukan penyebab awal yang tepat yang mendahuluinya pada baris terbawah dibagian I dari sertifikat kematian dengan menerapkan prinsip umum atau Rule 1, 2 dan 3 .

Berdasarkan observasi yang dilakukan peneliti terhadap kasus kematian di Rumah Sakit Umum Daerah Kota Salatiga, diketahui bahwa dalam penentuan kode Penyebab Dasar kematian masih belum sesuai dengan prosedur yang ditetapkan di dalam ICD-10 volume 2. Ketidaktepatan penentuan kode penyebab dasar kematian disebabkan karena petugas rekam medis menetapkan kode diagnosis utama pada lembar status pasien sebagai kode penyebab dasar kematian. Sebagai salah satu contohnya yaitu :

I (a) Cardiac Arrest (I46.9)

(b) Coma hepaticum (K72.9)

(c)Cirrhosis hepatic (K74.6),

Anemia berat (D50.0)

Pada urutan ini, petugas Coding menetapkan Cardiac Arrest (I46.9) yang tertulis sebagai diagnosis utama pada lembar status pasien sebagai kode Penyebab Dasar Kematian. Dalam sertifikat kematian Cardiac Arrest (I46.9) tidak diperbolehkan menjadi penyebab kematian karena dalam sertifikat kematian menyebutkan untuk penyebab kematian tidak boleh diisi cara meninggal (mode of dying) seperti Heart Failure, Respiratory Failure. Seharusnya penyebab kematian diisi dengan penyakit, cedera atau komplikasi yang menyebabkan kematian (DepKes, 2008). Karena aturan ini, maka diagnosis penyebab kematian yang dipilih tidak sesuai dengan aturan yang ada pada ICD-10. Setelah di cek menggunakan aturan yang ada dalam ICD-10 volume 2 dengan penerapan Rule 1 dengan bantuan Decision Table D, ternyata kode penyebab dasar kematian tersebut adalah Cirrhosis hepatic (K74.6). Prinsip umum tidak diterapkan karena terdapat lebih dari satu urutan yang berakhir dengan kondisi yang diisikan pertama pada sertifikat. Untuk menerapkan Rule 1 pada contoh diatas, kita perlu memeriksa hubungan kausal antara masing-masing kondisi yang tercantum pada 
sertifikat kematian. Adapun langkah-langkah yang harus ditempuh yaitu :

Langkah 1 :

Kita ingin menemukan penyebab asal kondisi yang pertama diisikan pada sertifikat kematian. Dalam kasus ini adalah Cardiac Arrest (I46.9), jadi apakah Coma hepaticum (K72.9) dapat menyebabkan Cardiac Arrest (I46.9)?

Carilah I46.9 sebagai address dalam tabel D, kita temukan address untuk I46.9 termasuk dalam rentang kode address ICD-10 (I440 -I509).

Cardiac Arrest (I46.9) bisa disebabkan oleh Coma hepaticum (K72.9) karena K72.9 ada dalam rentang kode I00-L599.

--- I440 -I509 ---

A000 -G98

M H000 -H959

I00 -L599 < (K72.9)

M L88 -L929

\# \# \# \# \# \# \# \#

Langkah 2

Sekarang kita perlu memeriksa apakah Cirrhosis hepatic (K74.6) ataupun Anemia berat (D50.0) dapat menyebabkan Coma hepaticum (K72.9). Kita bisa memeriksa keduanya pada saat yang bersamaan, kita cari address code K72.9 dalam tabel D dan memeriksa apakah K74.6 ataupun D50.0 tercantum sebagai sub address.

-- K729 ---
A000 -E899 $\quad<($ D50.0)
F100 -F169
F180 -F199
G000 -G129

G35 -G379

G937

I10 -K929 < (K74.6)

M000 -M1990

\# \# \# \# \# \# \# \#

Jadi Cirrhosis hepatic (K74.6) dan Anemia berat (D50.0) keduanya dapat menyebabkan Coma hepaticum (K72.9).

Karena Cirrhosis hepatic (K74.6) adalah penyebab asal dari urutan pertama yang berakhir dengan kondisi yang pertama disebutkan yaitu Cardiac Arrest (I46.9) maka Cirrhosis hepatic (K74.6) dipilih sebagai kode penyebab dasar kematian.

Dalam kasus ini, hal yang menyebabkan kesalahan atau ketidaktepatan adalah prosedur penentuan kode penyebab dasar kematian yang salah. Maka dari itu, dengan adanya prosedur atau rule dapat menuntun kita dalam penentuan kode penyebab dasar kematian.

Untuk menghasilkan ketepatan kode penyebab dasar kematian seharusnya petugas rekam medis (Coding) dapat menerapkan peraturan reseleksi yang meliputi penerapan prinsip umum, Rule 1, 2 atau 3 dalam proses penentuan kode penyebab dasar kematian di rumah sakit. Hal ini penting, agar dalam penentuan kode penyebab dasar kematian kita tidak menemukan lagi pemilihan kode yang salah dan mempermudah dalam pengolahan data, khususnya tentang data mortalitas menjadi akurat serta mempermudah dalam pengambilan keputusan.

\section{SIMPULAN}


Pemberian kode penyakit di Rumah Sakit Umum Daerah Kota Salatiga telah sesuai dengan tata cara coding pada ICD-10. Dalam menentukan kode penyakit, petugas koding memperhatikan tunjuk silang (cross references) juga mengikuti inclusion dan exclusion term dibawah kode atau dibawah chapter untuk mendapatkan kode yang tepat.

Ketepatan kode Penyebab Dasar kematian di Rumah Sakit Umum Daerah Kota Salatiga triwulan IV tahun 2010 sebanyak 22 kode $(78,57 \%)$ dan kode yang tidak tepat sebanyak 6 kode $(21,43 \%)$.

Cara penentuan kode penyebab dasar kematian di Rumah Sakit Umum Daerah Kota Salatiga masih berdasarkan kode dari diagnosis utama yang ditulis dokter dalam status pasien, hal ini belum sesuai dengan peraturan yang ada pada ICD-10 yaitu dalam menentukan kode penyebab dasar kematian petugas haruslah melakukan reseleksi dengan penerapan Rule, yang meliputi penerapan Prinsip Umum, Rule 1, Rule 2 atau Rule 3.

\section{DAFTAR PUSTAKA}

Arief, TQ. 2004. Pengantar Metodologi Penelitian Untuk Ilmu Kesehatan. Surakarta : CSGF (The Community of Self Help Group Forum). hal : 71 2009. Pengantar Metodologi Penelitian Untuk Ilmu Kesehatan. Surakarta : Lembaga Pendidikan (LPP) UNS dan UPT Penerbit dan Pencetakan UNS. hal : 45

Arikunto, Suharsini. 2010. Prosedur Penelitian(Suatu Pendekatan dan Praktik) Edisi Revisi X. Jakarta : PT Rineka Cipta.
DepDikNas. 2001. Kamus Bahasa Indonesia Edisi ke 3. Jakarta : Balai Pustaka.

DepKes RI. 2006. Pengelolaan Rekam Medis Rumah Sakit Di Indonesia Revisi II, Jakarta.

Hatta, Gemala. 2010. Pedoman Manajemen Informasi Kesehatan di Sarana Pelayanan Kesehatan. Edisi Revisi. Jakarta : Universitas Indonesia (UIPress).

Hidayat, A A. 2010. Metode Penelitian Kebidanan Teknik Analisis Data. Jakarta : Salemba Medika.

$\begin{array}{ccc}\text { KepMenKes } & \text { RI. } & \text { Nomor } \\ \text { 50/MENKES/SK/1/1998 } & \text { tentang } \\ \text { Pemberlakuan } & \text { Klasifikasi } & \text { Statistik } \\ \text { Internasional } & \text { Tentang } & \text { Penyakit } \\ \text { Revisi Ke-10. } & & \end{array}$

Kumala, Poppy. 1998. Kamus saku kedokteran dorland. Edisi 25. Jakarta.

Mansjoer, Arief. 2001. Kapita Selekta Kedokteran. Media Aesculapius FKUI: Jakarta. (halaman: 421-425)

Notoatmodjo, Soekijdo. 2010. Metodologi Penelitian Kesehatan. Edisi Revisi Pertama. Jakarta : PT Rineka Cipta.

PerMenKes RI. Nomor 269/MenKes/Per/III/2008 tentang Rekam Medis. Jakarta.

Sudra, R I. 2008. Kompetensi Perekam Medis. Diakses: 22 Maret 2012. http://www.ranocenter.net/modules. php?name $=$ News \&file $=$ article \&sid $=139$

Sugiyono. 2007. Statistika untuk penelitian. Revisi terbaru. Bandung : CV Alfabeta. Hal. 27

World Health Organization, 2005. International Statistical Clasification of Diseases And 
Related Health Problems(ICD-10, Volume 1), Geneva.

2005.International Statistical Clasification Of Diseases And Related Health Problems (ICD-10, Volume 2), Geneva.

2005.

International Statistical Clasification of Diseases And Related Health Problems (ICD-10, Volume 3), Geneva. 